\title{
Levamisole therapy in children with frequently relapsing and steroid-dependent nephrotic syndrome: a single-center experience
}

\author{
ELŻBIETA KUŹMA-MROCZKOWSKA, PIOTR SKRZYPCZYK, \\ MAEGORZATA PAŃCZYK-TOMASZEWSKA \\ Department of Pediatrics and Nephrology, Medical University of Warsaw, Poland
}

\begin{abstract}
Introduction: Numerous studies suggest that levamisole, an antihelmintic agent with an immunomodulatory effect, reduces the number of relapses in children with frequently relapsing and steroid-dependent nephrotic syndrome (FRNS/SDNS). The aim of the study was to present a single center's experience in treatment of FRNS and SDNS with levamisole.

Material and methods: Among 72 children with FRNS/SDNS treated in our department with levamisole in the years 1984-2011 we studied in detail 53 patients (mean age: $6.5 \pm 3.0$ years), in whom the medication was administered for at least 6 months. In these 53 patients we evaluated: the course of the disease before levamisole, the renal biopsy result, medications used, prednisone dose on levamisole initiation, duration of levamisole treatment, time to first relapse and number of relapses on levamisole, and levamisole side effects.

Results: The duration of nephrotic syndrome was $3.4 \pm 2.9$ years, and the number of relapses before levamisole treatment was $6.0 \pm 3.4$. The dose of prednisone on initiation of levamisole treatment was $1.2 \pm 0.6 \mathrm{mg} / \mathrm{kg} / 24 \mathrm{~h}$, and the duration of levamisole treatment was $15.0 \pm 7.3$ months. During levamisole treatment proteinuria relapsed in $34 / 53$ (64.2\%) children, and the time to first relapse was 8.8 \pm 8.1 months. During levamisole therapy relapses of the disease decreased significantly $(2.7 \pm 2.0 \mathrm{vs}$. $1.8 \pm 2.1$ relapses/year, $p=0.02)$. Time to first relapse correlated with total number of relapses $(R=-0.59$, $p<0.001)$ and number of relapses in one year during levamisole treatment $(R=-0.60, p<0.001)$.

Conclusions: Levamisole is effective in reducing the number of relapses in children with frequently relapsing and steroid-dependent nephrotic syndrome. Early relapse of proteinuria on levamisole treatment in children with FRNS/SDNS suggests low efficacy of further treatment.
\end{abstract}

Key words: children, immunomodulation, nephrotic syndrome, levamisole.

(Cent Eur J Immunol 2016; 41 (3): 243-247)

\section{Introduction}

Nephrotic syndrome is characterized by nephrotic range proteinuria (defined as urine protein : creatinine ratio $\geq 2000 \mathrm{mg} / \mathrm{g}$ ) and hypoalbuminemia (serum albumin level $\leq 2.5 \mathrm{~g} / \mathrm{dl}$ ), most commonly associated with hyperlipidemia and edema [1]. The most common cause of nephrotic syndrome in the pediatric population is idiopathic nephrotic syndrome (INS), present in $90 \%$ of children with nephrotic syndrome diagnosed between 1 and 10 years of age and in $50 \%$ of children with the diagnosis made at the age of $>10$ years [2]. The disease is more common in boys than in girls, and the incidence of INS is $2-7 / 100,000$ chil- dren $<15$ years of age, but the prevalence is $16 / 100,000$ due to the recurrent nature of the disease [3].

Corticosteroids are the treatment of choice in INS. Although about $80-90 \%$ of children with INS respond to corticosteroids, 20-30\% become steroid-dependent [1]. Chronic corticosteroid therapy in patients with steroiddependent or frequently relapsing NS (FRNS or SDNS) is associated with numerous side effects (e.g. growth retardation, obesity, osteoporosis, arterial hypertension, glaucoma, cataract, and psychoemotional changes) [4]. Also steroid-sparing immunosuppressive medications used in these patients (alkylating agents, calcineurin inhibitors,

Correspondence: Piotr Skrzypczyk, Department of Pediatrics and Nephrology, Medical University of Warsaw, Żwirki i Wigury 63 A, 02-091 Warsaw, Poland, e-mail: pskrzyp@gmail.com Submitted: 04.07.2016; Accepted: 18.08.2016 
rituximab) have many toxic, commonly irreversible adverse effects.

Levamisole is an antihelmintic agent with an immunomodulatory effect. Although its direct mechanism of action is not known, it is postulated that levamisole enhances the Th1 lymphocyte-mediated immune response and reciprocally down-regulates the Th2 lymphocytemediated immune response via selective induction of transcription of several genes, e.g. the interleukin 18 gene [5] and, probably, via activation and induction of maturation of dendritic cells [6]. Moreover, it potentiates monocyte and macrophage functions, including phagocytosis and chemotaxis, and increases neutrophil mobility, adherence, and chemotaxis [7]. Recently, it was suggested that levamisole's mode of action is attributable to its direct effects on podocytes. Jiang reported that levamisole induced expression of glucocorticoid receptor (GR) and activated GR signaling in podocytes. Furthermore, levamisole was able to protect against podocyte injury in a puromycin aminonucleoside (PAN)-treated cell model [8].

Numerous studies suggest that levamisole reduces the frequency of relapses and corticosteroid doses in children with FRNS and SDNS [8-16]. In most cases levamisole therapy did not cause any severe side effects. Most commonly (1-2\%) reversible leucopenia, sporadically liver toxicity, seizures, gastrointestinal symptoms, psoriasis-like cutaneous reaction, and vasculitis were noted [17-19].

The aim of this study was to present a single center's experience in the treatment of frequently relapsing and steroid-dependent nephrotic syndrome with levamisole.

\section{Material and methods}

We studied retrospectively 72 children (41 boys, 31 girls) aged from 1.9 to 15.6 (median age: 5.6 years) with SDNS/ FRNS treated in our department with levamisole in the years 1984-2011.

In all studied children the following parameters were evaluated: age of first bout of the disease [years], duration of the disease [years], number of nephrotic syndrome relapses and proteinuria relapses before levamisole treatment $[n, n /$ year $]$, result of renal biopsy, medications used before levamisole treatment, prednisone dose on levamisole initiation $[\mathrm{mg} / \mathrm{kg} / 24 \mathrm{~h}]$, duration of levamisole treatment [months], duration of prednisone treatment during levamisole therapy [months], time to first NS/proteinuria relapse on levamisole treatment [months], number of proteinuria/ NS relapses during levamisole treatment [ $n, n /$ year], and adverse events of the treatment.

Nephrotic syndrome was defined as proteinuria $\geq 50 \mathrm{mg} / \mathrm{kg} / 24 \mathrm{~h}$ or protein : creatinine ratio $\geq 2000 \mathrm{mg} / \mathrm{g}$, hypoalbuminemia $(\leq 2.5 \mathrm{~g} / \mathrm{dl})$ with hyperlipidemia and edema. Relapse of NS was defined as 3 days of nephrotic proteinuria, most commonly with accompanying hypoalbuminemia, hyperlipidemia, and edema, and remission as 3 consecutive days without proteinuria in urinalysis or daily urinary collection. Nephrotic syndrome classification was based on response to corticosteroids. Patients who achieved remission during an 8-week course of corticosteroid therapy were considered as having steroid-sensitive NS, patients with two or more relapses within 6 months of the initial response or with four or more relapses in any 12-month period as having frequently relapsing NS, patients with 2 consecutive relapses during tapering of the corticosteroid dose or within 14 days after corticosteroid withdrawal as having steroid-dependent NS, finally, patients not achieving remission within 8-week corticosteroid treatment were defined as having steroid-resistant NS [1].

The first attack of NS was treated with prednisone in the dose of $60 \mathrm{mg} / \mathrm{m}^{2} / 24 \mathrm{~h}$ or $2 \mathrm{mg} / \mathrm{kg} / 24 \mathrm{~h}$ (not exceeding $60 \mathrm{mg} / 24 \mathrm{~h}$ ) for $4-6$ weeks, then in the same dose every 48 hours for 4 weeks, with gradual tapering of the dose within the next month (years 1970-1995) or 4 months (after 1995). Nephrotic syndrome relapses were treated with the same protocol as the first attack.

Levamisole treatment was started in case of steroid dependence with long-term corticosteroid therapy [35 $(48.6 \%)$ children] or intensified side effects of corticosteroid therapy [obesity in $22(30.6 \%)$, growth retardation in $6(8.3 \%)$, hirsutism in $5(6.9 \%)$, arterial hypertension in $3(4.2 \%)$, and cataract in $1(1.4 \%)$ child].

Levamisole was administered according to the following protocol: in the first month $2.5 \mathrm{mg} / \mathrm{kg} / 48 \mathrm{~h}$, and in the following months $2.5 \mathrm{mg} / \mathrm{kg}$ twice weekly. In every case levamisole was started in patients in remission of NS. During levamisole treatment in all patients we evaluated complete blood count and transaminases one week after initiation of therapy and then every 4 weeks. Hypertransaminasemia was defined as a rise of liver enzymes above the reference range and neutropenia as a drop in neutrophil count below the reference range. Detailed analysis was performed in those children treated with levamisole for at least 6 months.

Results were presented as mean \pm standard deviation and range. Result series were tested for normality with the Shapiro-Wilk test. The following tests were used: Student's $t$ test, Mann-Whitney $U$ test, Wilcoxon test, Fisher's exact test, Kaplan-Meier analysis, Pearson linear correlation, and Spearman's rank correlation, when appropriate. The statistical significance level was defined as $p<0.05$.

\section{Results}

Among 72 studied children $53(73.6 \%)$ were treated with levamisole for at least 6 months. Baseline characteristics of these 53 children are presented in Table 1. Among studied children there was a slight prevalence of boys. Mean duration of INS was about 3 years, and mean number of relapses before levamisole treatment was about 6 . All children were treated with oral corticosteroids, and 18 (34.0\%) were given other medications, most commonly methylprednis- 
olone pulses. Renal biopsy was performed in 24 out of 53 patients $(45.3 \%)$, mostly before the year 1995 , with mesangial proliferation being the most common finding.

Treatment with levamisole is presented in Table 2. The mean dose of prednisone on initiation of levamisole treatment was $1.2 \mathrm{mg} / \mathrm{kg} / 24 \mathrm{~h}$, and the mean duration of levamisole treatment was 1 year and 3 months. During levamisole treatment proteinuria relapsed in $34(64.2 \%)$ out of 53 children. Twenty-seven (79.4\%) out of those 34 children also received prednisone when proteinuria relapsed. Twenty-three children relapsed during the first 6 months, with 8 relapsing in the following half-year, and the remaining 3 relapsed during the second year of levamisole treatment. In 19 (35.8\%) children there were no recurrences of proteinuria during levamisole treatment (mean duration of levamisole treatment in this group was $14.2 \pm 6.0$ months). Three children treated with levamisole for 15,16 , and 23 months were free of proteinuria even after levamisole was stopped, for 20, 27, and 37 months, respectively. Maintenance of remission in children with INS treated with levamisole is presented in Figure 1. The number of relapses per year before and during levamisole therapy is presented in Figure 2. During treatment with levamisole in children with INS the number of relapses of the disease significantly decreased $(2.7 \pm 2.0$ vs. $1.8 \pm 2.1, p=0.02)$.

In the whole group of 53 children we found negative correlations between time to first relapse of proteinuria and total number of relapses $(\mathrm{R}=-0.59, p<0.001)$ and number of relapses in one year $(\mathrm{R}=-0.60, p<0.001)$ during levamisole treatment.

Adverse events of levamisole treatment were found in 16 out of $72(22.2 \%)$ children treated with levamisole: allergic rash in 9, abdominal pain in 3, hypertransaminasemia in 3 , arthralgia in 2 , leucopenia in 1 , thrombocytopenia in 1 . All side effects were transient and fully reversible after levamisole withdrawal.

\section{Discussion}

Numerous immunosuppressive agents are used in the treatment of frequently relapsing and steroid-dependent nephrotic syndrome in order to limit the doses of corticosteroids. Due to many serious, commonly irreversible adverse events of these drugs, new medications with a good safety profile are sought. Levamisole is a well-known antihelmintic agent with immunomodulatory action. It should be emphasized that use of levamisole is severely limited due to its unavailability in many European countries. Thus, most patients import the medication on their own from countries where it is available as an antihelmintic agent.

Tanphaichitr was the first to describe the role of levamisole in the treatment of childhood idiopathic nephrotic syndrome in 1980 [9]. The effectiveness of levamisole in reducing the frequency of relapses in children with FRNS and SDNS is well documented [4, 10-16]. Thus,
Table 1. Baseline characteristics of the studied children with idiopathic nephrotic syndrome treated with levamisole for at least 6 months

\begin{tabular}{lc}
\hline Number of patients & 53 \\
\hline Sex (boys/girls) & $31 / 22(58.5 \% / 41.5 \%)$ \\
\hline Age (years) & $6.5 \pm 3.0(1.9-14.8)$ \\
\hline Age at onset of INS (years) & $3.1 \pm 2.0(1.0-9.8)$ \\
\hline Duration of the disease (years) & $3.4 \pm 2.9(0.5-12.0)$ \\
\hline Number of relapses $(\boldsymbol{n})$ & $6.0 \pm 3.4(2-15)$ \\
$(\boldsymbol{n} / \mathbf{y}$ ear) & $2.7 \pm 2.0(0.4-12)$ \\
\hline Renal biopsy $(\boldsymbol{n})$ & $24(45.3 \%)$ \\
Minimal change $(\boldsymbol{n})$ & $4(7.5 \%)$ \\
Mesangial proliferation $(\boldsymbol{n})$ & $20(37.7 \%)$ \\
\hline Treatment before levamisole therapy & \\
\hline Oral corticosteroids $[n]$ & $53(100.0 \%)$ \\
\hline Methylprednisolone pulses $[n]$ & $13(24.5 \%)$ \\
\hline Cyclophosphamide $[n]$ & $10(18.9 \%)$ \\
\hline Chlorambucil $[n]$ & $8(15.1 \%)$ \\
\hline Cyclosporine A $[n]$ & $1(1.9 \%)$ \\
\hline Azathioprine $[n]$ & $1(1.9 \%)$ \\
\hline
\end{tabular}

Table 2. The course of nephrotic syndrome during levamisole treatment

\begin{tabular}{lc}
\hline $\begin{array}{l}\text { Corticosteroid dose on initiation } \\
\text { of levamisole treatment }(\mathbf{m g} / \mathbf{k g} / \mathbf{2 4} \mathbf{~ h})\end{array}$ & $\begin{array}{c}1.2 \pm 0.6 \\
(0.1-2.0)\end{array}$ \\
\hline $\begin{array}{l}\text { Duration of levamisole treatment } \\
\text { (months) }\end{array}$ & $\begin{array}{c}15.0 \pm 7.3 \\
(6.0-31.0)\end{array}$ \\
\hline Duration of corticosteroid treatment & $8.7 \pm 8.5$ \\
during levamisole therapy (months) & $(1.0-31.0)$ \\
\hline Time to relapse on levamisole & $8.8 \pm 8.1$ \\
treatment (months) & $(0.5-37.0)$ \\
\hline Number of relapses on levamisole & $1.9 \pm 2.1(0-9)$ \\
treatment $(\boldsymbol{n}) ;(\boldsymbol{n} / \mathbf{y e a r})$ & $1.8 \pm 2.1(0.0-8.0)$ \\
\hline
\end{tabular}

treatment with levamisole significantly reduces the cumulative dose of steroid intake, as was proven by Al-Saran [4] and Ekambaram et al. [20]. It should be stressed that only a few of these studies were randomized controlled trials [10-12]. The results of an international multicentre placebo-controlled trial are to be released this year. Interestingly, levamisole was found to be equally effective as cyclophosphamide in maintaining remission in children with steroid-dependent/frequently relapsing nephrotic syndrome [13, 21]. On the other hand, Moustafa and Tolba found the highest resistance to treatment (defined as failure to induce 6-month remission) in FRNS/SDNS children on levamisole $(n=40)$ compared to those treated with cyclophosphamide, cyclosporine A, mofetil mycophenolate or azathioprine [22]. Also, in a recently published retrospective study by Basu et al. tacrolimus was significantly 


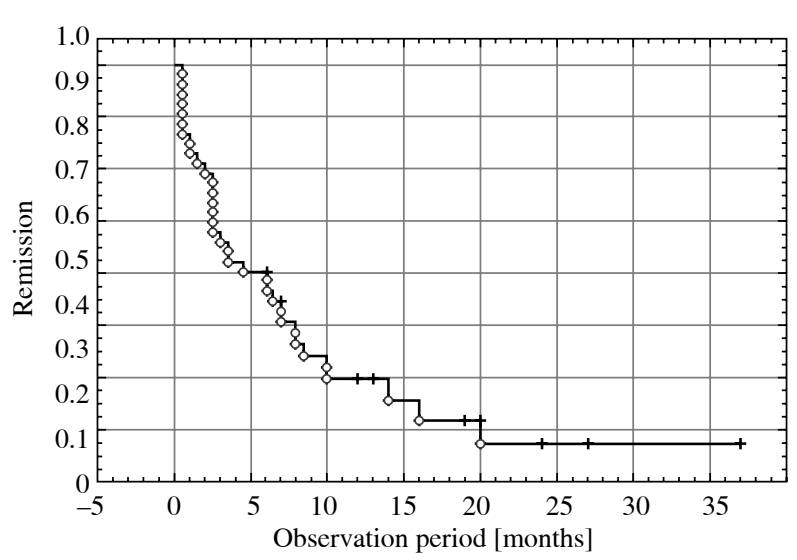

Fig. 1. Maintenance of remission in children with idiopathic nephrotic syndrome treated with levamisole

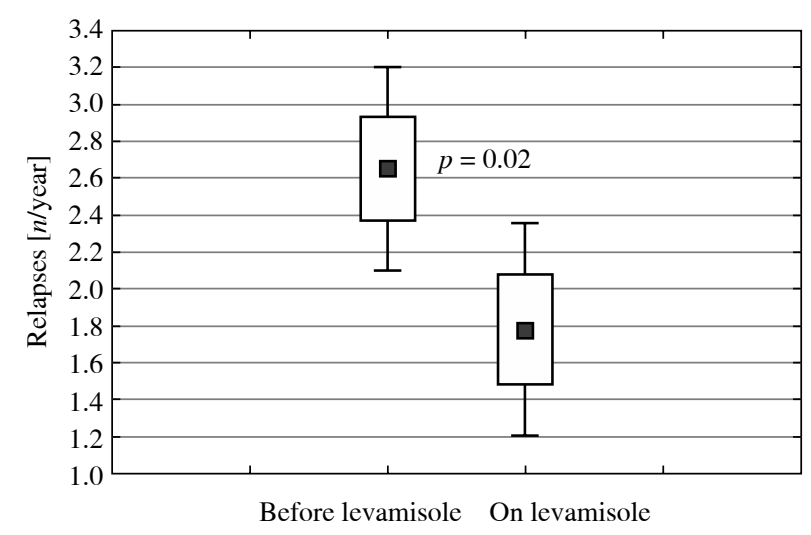

Fig. 2. Number of relapses in children with idiopathic nephrotic syndrome before and during levamisole treatment

more effective than mofetil mycophenolate or levamisole in maintaining relapse-free survival over a period of 30 months in a cohort of 340 children with FRNS/SDNS [23]. Nevertheless, taking into account its low cost and good safety profile, we believe that in the era of modern immunosuppressive medications such as mofetil mycophenolate, tacrolimus, and rituximab there is still a place for levamisole application in children with INS.

In our group of patients we were also able to prove a significant reduction in the number of INS relapses. In three patients remission was maintained long after levamisole was stopped. This observation is in accordance with the results of recent studies suggesting that its steroidsparing effects last for months after its withdrawal [13, 20, 24, 25]. Boyer et al. [25], Elmas et al. [24], and Ekambaram et al. [20] found that in some children levamisole has a long-lasting effect even 12 months after withdrawal.

There is no clear answer to the protocol of prednisone tapering in children on levamisole treatment. In the study of the British Association of Pediatric Nephrologists
(BAPN) prednisolone was withdrawn after 56 days of combined therapy. After 112 days significantly more children receiving levamisole were in remission compared to the control group $(14 / 31$ vs. $5 / 30, p<0.01)$ [10]. Al-Saran compared in a prospective study the effectiveness of levamisole and a low corticosteroid dose $(<0.5 \mathrm{mg} / \mathrm{kg} / 48 \mathrm{~h})$ in maintaining remission in children with FRNS/SDNS. The rate of prednisolone tapering was $10 \mathrm{mg} / \mathrm{m}^{2} / 48 \mathrm{~h}$ every 8 days. Patients on levamisole therapy were characterized by a significantly lower number of relapses and higher reduction of steroid dose compared to the control group [4]. It should be noted that the frequency of relapses during levamisole therapy was $0.96 \pm 1.80$ /patient/year, which is much less than in our population (1.9 \pm 2.1 /patient/year). Similarly, in the study by Bagga et al. prednisolone was tapered by $2.5-5 \mathrm{mg}$ every 4 weeks to $0.5 \mathrm{mg} / \mathrm{kg}$ on alternate days. In this cohort the number of relapses was also reduced from $3.0 \pm 1.5$ to $0.9 \pm 0.7 /$ patient/year [15]. It should be stressed that in the studies by Al-Saran and Bagga levamisole was administered, unlike in our protocol, at a dose of $2.5 \mathrm{mg} / \mathrm{kg}$ on alternate days for the whole period of therapy $[4,15]$.

In our study group time to first relapse on levamisole treatment correlated negatively with number of relapses in further observation. Thus, we can conclude that early recurrence of proteinuria is highly suggestive of ineffectiveness of levamisole.

Levamisole was proven to be safe in our patients. Side effects were not rare, though they were mild in nature and fully reversible after withdrawal of the medication. Incidence of side effects of levamisole treatment in children with INS varies from no adverse events [4, 20, 23] to $14.7 \%$ [26]. Like in our patients, most cases of adverse events do not pose a serious risk for a patient. More severe cases are sporadically reported, such as disseminated autoimmune disease with high titers of IgM anticardiolipin and p-ANCA antibodies described by Barbano et al. [17].

The limitations of our study are the retrospective design and small number of patients with relatively high diversity in age and treatment protocols, which could have influenced the response to levamisole treatment. Also, due to the retrospective nature of our study it was impossible to determine in many patients the dose of corticosteroids administered during the relapse of nephrotic syndrome while on levamisole treatment, and we did not include these data in our paper. In addition, our study was uncontrolled and, since spontaneous improvement occurs commonly in patients with INS, especially during puberty, we cannot rule out this factor in our patients.

\section{Conclusions}

1. Levamisole is effective in reducing the number of relapses in children with frequently relapsing and steroid-dependent nephrotic syndrome. 
2. Early relapse of proteinuria on levamisole treatment in children with FRNS/SDNS suggests low efficacy of further treatment.

The authors declare no conflict of interest.

\section{References}

1. Kidney Disease: Improving Global Outcomes (KDIGO) Glomerulonephritis Work Group (2012): KDIGO Clinical Practice Guideline for Glomerulonephritis. Kidney Int Suppl 2: 139-274.

2. Lombel RM, Hodson EM, Gipson DS (2013): Treatment of steroid-resistant nephrotic syndrome in children: new guidelines from KDIGO. Pediatr Nephrol 28: 409-414.

3. A report of the International Study of Kidney Disease in Children (1978): Nephrotic syndrome in children: prediction of histopathology from clinical and laboratory characteristics at time of diagnosis. Kidney Int 13: 159-165.

4. Al-Saran K, Mirza K, Al-Ghanam G, Abdelkarim M (2006): Experience with levamisole in frequently relapsing, steroiddependent nephrotic syndrome. Pediatr Nephrol 21: 201-205.

5. Szeto C, Gillespie KM, Mathieson PW (2000): Levamisole induces interleukin 18 and shifts THI/TH2 balance. Immunology 100: 217-222.

6. Chen LY, Lin YL, Chiang BL (2007): Levamisole enhances immune response by affecting the activation and maturation of human monocyte-derived dendritic cells. Clin Exp Immunol 151: 174-181.

7. Renoux G (1980): The general immunopharmacology of levamisole. Drugs 20: 89-99.

8. Jiang L, Dasgupta I, Hurcombe JA, et al. (2015): Levamisole in steroid-sensitive nephrotic syndrome: usefulness in adult patients and laboratory insights into mechanisms of action via direct action on the kidney podocyte. Clin Sci (Lond) 128: 883-893.

9. Tanphaichitr P, Tanphaichitr D, Sureeratanan J, Chatasingh S (1980): Treatment of nephrotic syndrome with levamisole. J Pediatr 96: 490-493.

10. British Association for Pediatric Nephrology (1991): Levamisole for corticosteroid dependent nephrotic syndrome in childhood. Lancet 337: 1555-1557.

11. Dayal U, Dayal AK, Shastry JC, Raghupathy P (1994): Use of levamisole in maintaining remission in steroid sensitive nephrotic syndrome in children. Nephron 66: 408-412.

12. Rashid HU, Ahmed S, Fatima N, Khanam A (1996): Levamisole in the treatment of steroid dependent or frequent relapsing nephrotic syndrome in children. Bangladesh Ren J 15: 6-8.

13. Al-Saran K, Grisaru S, Stephens D, Arbus G (2001): Levamisole vs. cyclophosphamide for frequently relapsing steroiddependent nephrotic syndrome. Clin Nephrol 56: 289-294.

14. Niaudet P, Drachman R, Gagnadoux MF, Broyer M (1994): Treatment of idiopathic nephrotic syndrome with levamisole. Acta Pediatr Scand 73: 637-641.

15. Bagga A, Sharma A, Srivastava RN (1997): Levamisole therapy in corticosteroid dependent nephrotic syndrome in children. Pediatr Nephrol 11: 415-447.

16. Donia AF, Amer GM, Ahmed HA, et al. (2002): Levamisole: adjunctive therapy in steroid-dependent minimal change nephrotic children. Pediatr Nephrol 17: 355-358.
17. Barbano G, Ginevri F, Ghiggeri GM, Gusmano R (1999): Disseminated autoimmune disease during levamisole treatment of nephrotic syndrome. Pediatr Nephrol 13: 602-603.

18. Bulugahapitiya DT (1997): Liver toxicity in a nephrotic patient treated with levamisole. Arch Dis Child 76: 289.

19. Palcoux JB, Niaudet P, Goumy P (1994): Side effects of levamisole in children with nephrosis. Pediatr Nephrol 8: 263264.

20. Ekambaram S, Mahalingam V, Nageswaran P, et al. (2014): Efficacy of levamisole in children with frequently relapsing and steroid-dependent nephrotic syndrome. Indian Pediatr 51: 371-373.

21. Donia AF, Ammar HM, El-Agroudy Ael-B, et al. (2005): Long-term results of two unconventional agents in steroid-dependent nephrotic children. Pediatr Nephrol 20: 1420-1425.

22. Moustafa BH, Tolba OA (2016): Immunosuppressive therapy in children with steroid-resistant, frequently-relapsing, and steroiddependent idiopathic nephrotic syndrome: a single center experience. Electron Physician 8: 2039-2047.

23. Basu B, Babu BG, Mahapatra TK (2016): Long-term efficacy and safety of common steroid-sparing agents in idiopathic nephrotic children. Clin Exp Nephrol [Epub ahead of print]; doi: 10.1007/s10157-016-1266-8.

24. Elmas AT, Tabel Y, Elmas ON (2013): Short- and long-term efficacy of levamisole in children with steroid-sensitive nephrotic syndrome. Int Urol Nephrol 45: 1047-1055.

25. Boyer O, Moulder JK, Grandin L, Somers MJ (2008): Short and long-term efficacy of levamisole as adjunctive therapy in childhood nephrotic syndrome. Pediatr Nephrol 23: 575-580.

26. Sümegi V, Haszon I, Iványi B, et al. (2004): Long-term effects of levamisole treatmentin childhood nephrotic syndrome. Pediatr Nephrol 19: 1354-1360. 